\title{
PROJETO DE UMA ÁREA DE LAZER EDUCATIVA PARA O DESENVOLVIMENTO SUSTENTÁVEL
}

Luiz.Eduardo Rosa - luizeduardo.rosa99@gmail.com

Universidade Federal de Santa Catarina

Rua Dona Francisca

89219-600 - Joinville - Santa Catarina

Heloisa Prestes da Silva - Heloisaprestes24@gmail.com

Universidade Federal de Santa Catarina

Rua Dona Francisca

89219-600 - Joinville - Santa Catarina

Carlos Mauricio Sacchellí - Carlos.sacchelli@gmail.com*

Universidade Federal de Santa Catarina

Rua Dona Francisca

89219-600 - Joinville - Santa Catarina

Resumo: A sustentabilidade está atualmente sendo um tema constante nas mais diversas áreas, visando aliar este tema e a demanda por áreas de convivência na universidade o Programa de Educação Tutorial das Engenharias da Mobilidade (PET EMB) desenvolveu o projeto Área de Lazer Educativa ou Sustentável com o intuito de preencher essa lacuna. $O$ projeto aconteceu por meio de parceria com a comunidade na Semana Nacional de Ciência e Tecnologia (SNCT) de 2019 em uma oficina ministrada para colégios públicos da cidade de Joinville, Santa Catarina, em que foram confeccionados bancos com materiais de fácil acesso e baixo custo. A iniciativa foi um sucesso, presenteando a comunidade acadêmica da Universidade Federal de Santa Catarina, no campus de Joinville, com uma nova área de lazer para os estudantes, professores e servidores.

Palavras-chave: Lazer. Sustentabilidade. Extensão. 


\section{INTRODUÇÃO}

A indústria da Construção Civil é considerada uma das mais importantes para o desenvolvimento econômico e social, mas por outro lado, é a atividade com maior impacto sobre o meio ambiente. Estima-se que a cadeia produtiva da construção civil consome entre 20 e $50 \%$ dos recursos naturais do planeta. (BRASILEIRO; MATOS, 2015).

A geração de resíduos é diretamente proporcional ao crescimento e desenvolvimento de uma sociedade e a humanidade torna-se cada vez mais urbana. (TESSARO; SÁ; SCREMIN, 2012). Com a urbanização acelerada e crescimento do setor construtivo, a geração de resíduos alcançou índices alarmantes.

Esses resíduos, produto do desperdício nas obras de construções, reformas, demolições e até mesmo de catástrofes naturais, se depositados irregularmente causam enchentes, proliferação de vetores de doenças e degradação do ambiente urbano (JOHN;AGOPYAN, 2000).

Devido ao alto número de resíduos produzidos, produtos e métodos construtivos sustentáveis foram criados ao longo do tempo e essa prática, ainda de alto custo, se torna mais comum, visto que o valor sustentabilidade tem se tornado maior do que o valor monetário. A construção sustentável é um método que promove intervenções sobre o meio ambiente, sem esgotar os recursos naturais, preservando-os para as gerações futuras. (PEREIRA, 2009).

Alguns métodos utilizados são a redução do consumo de matéria prima através da redução e reciclagem de resíduos, aperfeiçoamento de projetos, substituição de materiais tradicionais por outros mais eficientes, redução do consumo de energia e redução global da poluição. (BRASILEIRO; MATOS, 2015).

O XIVII Congresso Brasileiro e II Simpósio Internacional de Educação em Engenharia da Abenge (2019) reforça a importância do incentivo ao pensamento críticos em questões ambientais e de sustentabilidade no ensino superior, principalmente em cursos de engenharia, que, futuramente, formarão profissionais aptos a desenvolver técnicas e produtos mais sustentáveis no mercado de trabalho.

Além dos incentivos externos, podemos notar grande apoio das universidades e entidades pertencentes, como é o exemplo dos graduandos em Engenharia de Materiais da Universidade Federal de Itajubá, que desenvolveram um veículo off-roadutilizando materiais plásticos e reciclados. (JUSTINO et al.; 2018). Estudantes de Engenharia Civil do CEFET-MG, com o apoio do grupo PET, realizaram um fórum voltado a temática de Cidades Sustentáveis, com a participação de palestrantes e ministrantes de minicursos com notória experiência em suas áreas de atuação. (FIALHO el at.; 2018).

O PET é um programa, que surgiu na década de 70, chamado de Programa Especial de Treinamento, passando apenas em 2004 a ser chamado de Programa de Educação Tutorial (PET). (CARVALHO et al., 2018).

O PET é formado por grupos de estudantes das Instituições de Ensino Superior (IES) do País, com a tutoria de um docente, no intuito de desenvolver projetos para aplicar seus conhecimentos e ampliar a sua formação. (FUNDO, 2020).

Segundo o Ministério da Educação (2020), atualmente com 842 grupos divididos em 121 IES, o PET é regido pelo princípio indissociabilidade entre ensino, pesquisa e extensão.

Na UFSC atualmente tem-se 23 grupos PET e no campus de Joinville 1 grupo, denominado de Centro de Engenharias da Mobilidade, sendo composto por 12 estudantes e 1 professor.

Visando a sustentabilidade e a demanda por áreas de convivência na universidade, o Programa de Educação Tutorial das Engenharias da Mobilidade desenvolveu o projeto com o intuito de preencher essas lacunas. Além de projetos de ensino, pesquisa e extensão, o PET EMB abraça diversas causas e a sustentabilidade é uma delas. Aumentando o portfólio que já 
incluía projetos como a reutilização de cápsulas de café, recolhimento de tampas plásticas e oficinas de compostagem.

No ano de 2019, foi desenvolvido o projeto denominado de Área de Lazer, projetando um espaço dedicado a interação entre estudantes e servidores do campus com conceitos de sustentabilidade. Assim, o objetivo deste trabalho será de apresentar as atividades que foram realizadas pelo grupo nesta ação.

\section{PROJETO}

O projeto tinha como objetivo principal oferecer a comunidade acadêmica da Universidade Federal de Santa Catarina, campus Joinville, uma área para lazer e descanso nas horas vagas através de materiais reutilizados dos laboratórios de construção civil do campus, que pudesse também servir de reflexão sobre alguns conceitos de sustentabilidade.

Inicialmente foi realizado um projeto que contasse com lugares para sentar, plantas, sombra para os dias com sol além de uma área de compostagem e uma pequena horta.

A discussão do projeto ocorreu em 2019 no primeiro semestre, quando foram definidos os objetivos e principais ideias. No segundo semestre de 2019 iniciou-se a parte prática e o projeto saiu do papel.

A Figura 1 apresenta o painel semântico inicial do projeto, desta maneira se deseja que esta área deveria ser agradável, ter plantas, possuir itens relacionado a educação sustentável, pois recebemos com grande frequências grupos de escolas que visitam o campus, sendo muito interessante levar a discussão sobre o desenvolvimento sustentável para os visitantes.

Figura 1. a) Espaço cobertura com lugar para sentar. b) Horta com material reciclado. c) Uso de material de construção. d) Espaço para descansar.

a)

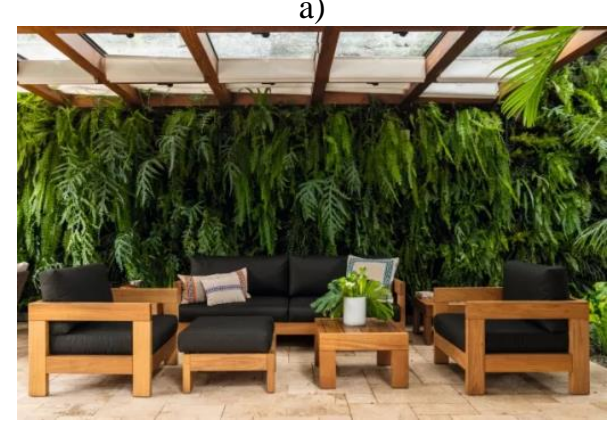

c)

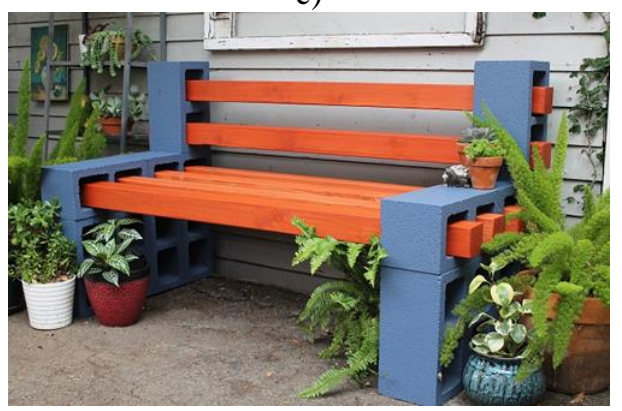

b)

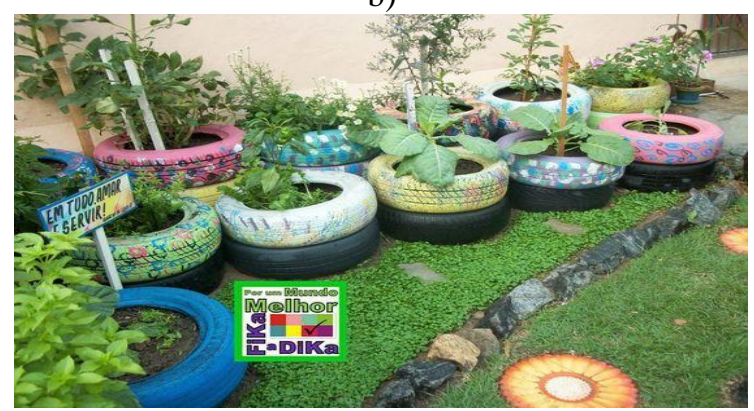

d)

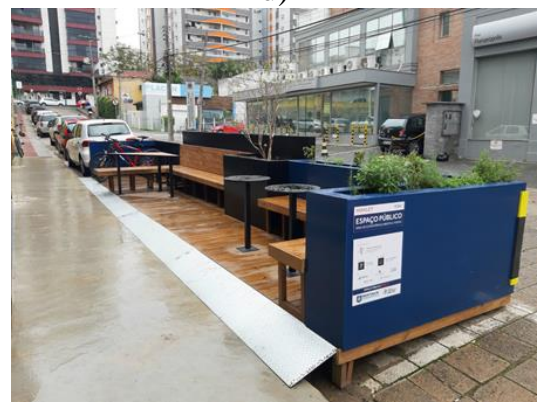

Fonte:a-https://revistacasaejardim.globo.com/Casa-e-Comida/Receber-com-charme/Decoracao/noticia/2019/06/11-projetos-compergolado-para-se-inspirar.html

b-https://br.pinterest.com/pin/511440101418527343/

c-https://www.casafa.net/faca-voce-mesmo/como-construir-sozinho-um-banco-com-materiais-reciclados/

d-https://floripacentro.com.br/espacos-para-convivencia-nas-ruas-tres-parklets-embelezam-e-ajudam-a-humanizar-locais-publicos-no-centro/

Com base nos requisitos de projeto, definiu-se que a área poderia conter de dois a três 
bancos. O projeto poderia ser por etapas, em que primeiramente se produz os banco e posteriormente, pensar em formas de fazer com que a área remetesse à sustentabilidade. Portanto, desde os materiais escolhidos, até mesmo as cores das tintas foram pensadas com o intuito de remeter aos ideais sustentáveis.

Foi pensado também formas de decorar e preencher essa área, como por exemplo, pergolados, jardins verticais, áreas de compostagem, entre outros.

Para os bancos, o projeto escolhido foi com blocos de concreto e madeira (fig. 2), objetivando compor essa área de lazer a partir de materiais simples e de fácil manuseio, comprados em lojas de construção civil.

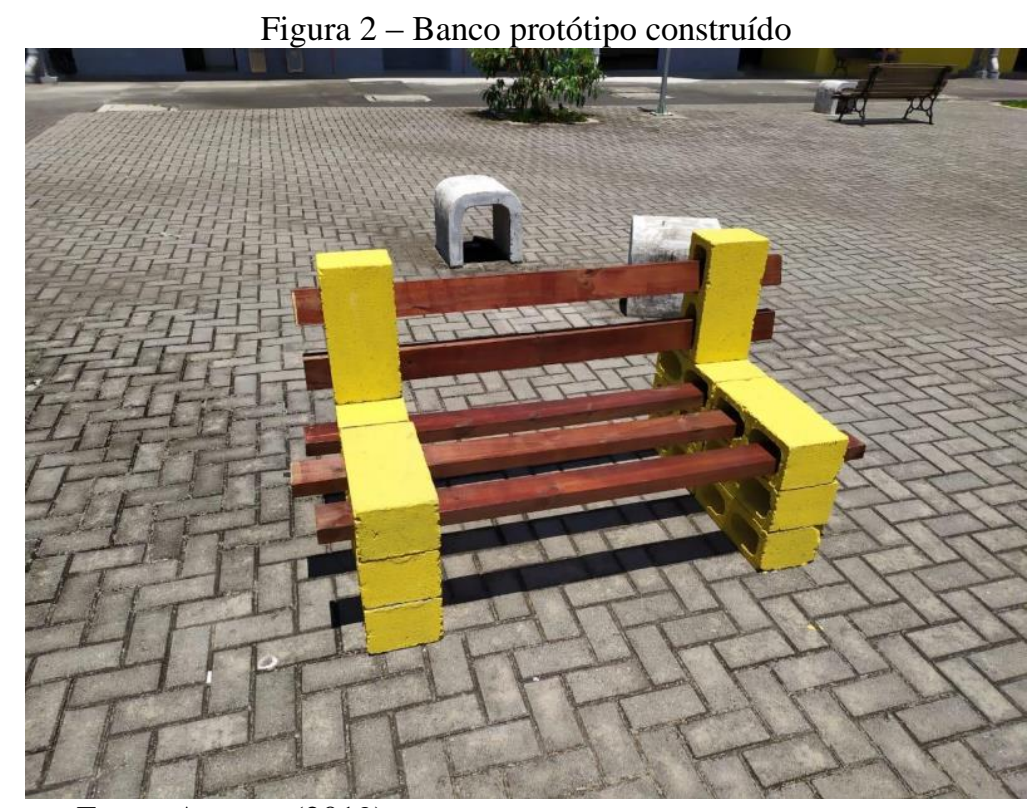

Fonte: Autores (2019)

Dessa forma, os seguintes materiais para a confecção de cada banco foram adquiridos:

- 14 blocos de concreto

- 1 bisnaga de argamassa

- 5 vigas de madeira de pinus auto clavada $(5 \times 10 \times 1,5 \mathrm{~cm})$

- 1 lixa

- 1 lata de Tinta de quadra

- 1 lata de verniz

- Materiais para pintura

Para montar os demais bancos, pensou-se em fazer uma oficina com estudantes de escolas públicas de Joinville na Semana Nacional de Ciência e Tecnologia (SNCT 2019).

Para a confecção dos bancos, primeiramente, para otimização do tempo, antes da oficina foram pintados todos os blocos de concretos pelos membros do PET EMB. Além dos blocos, cada viga de madeira foi devidamente lixada e vernizada.

No protótipo montado inicialmente continha dois blocos de cada lado de base, e o apoio das costas ao final dos mesmos (Fig. 1c). O apoio ficava muito longe da borda, assim, a ergonomia não estava muito boa, pois os pés ficavam longe do chão.

Uma alteração foi realizada, onde o bloco do apoio foi deslocado mais para frente e inserido mais uma fileira o banco, fazendo com que o banco pudesse ser utilizado em ambos 
C. COBENCE N2020

"Os desafios para formar hoje o engenheiro do amanhã"
$\mathrm{Ol}$ a $\mathrm{O3}$ de dezembro Evento On-line

os lados.

No dia da oficina no evento da SNCT 2019, com o auxílio dos estudantes, foram formadas 4 pilhas de blocos de concreto, com 3 blocos em cada, todos na horizontal. Entre um bloco de concreto e outro, foi colocado argamassa. Foi enfileirado duas pilhas de blocos de cada lado e na ponta de cada pilha foi colocado um bloco de concreto na vertical, para o apoio das costas.

Depois de certo tempo para a argamassa secar foi possível encaixar as vigas de madeiras nos blocos de concreto, finalizando a montagem dos bancos.

\section{RESULTADOS E DISCUSSÕES}

O bloco utilizado possui dimensões de 39 × 19 x $14 \mathrm{~cm}$ (Figura 3a), o projeto inicial possuía as cotas de acordo com a Figura $3 b$.

Figura 3. a) Dimensão Bloco. b) Projeto Inicial.

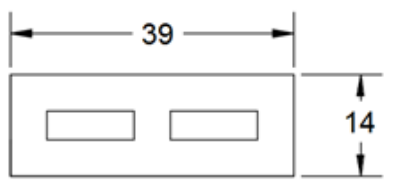

a)

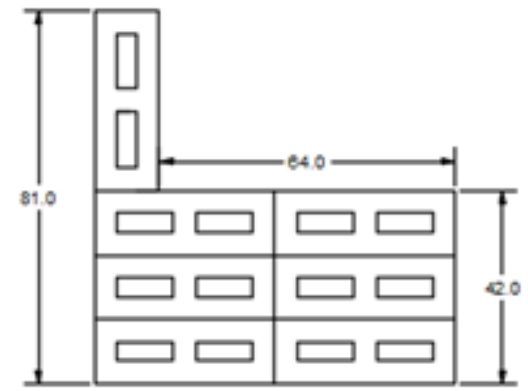

b)

Como comentado anteriormente o projeto foi alterado, pois a distância de $64 \mathrm{~cm}$ após alguns testes não foi considerada ergonômica.

A nova conta foi de aproximadamente $51 \mathrm{~cm}$, sendo observado que poderíamos inserir mais blocos e com isso dobrar a capacidade do banco.

Desta maneira o novo projeto ficou com as cotas de acordo com a Figura 4.

Figura 4. a) vista lateral e b) vista frontal

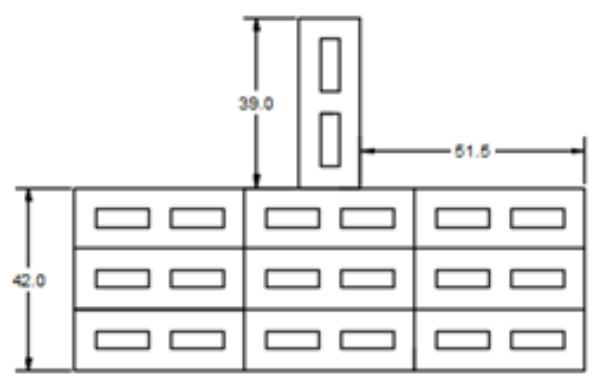

a) vista lateral

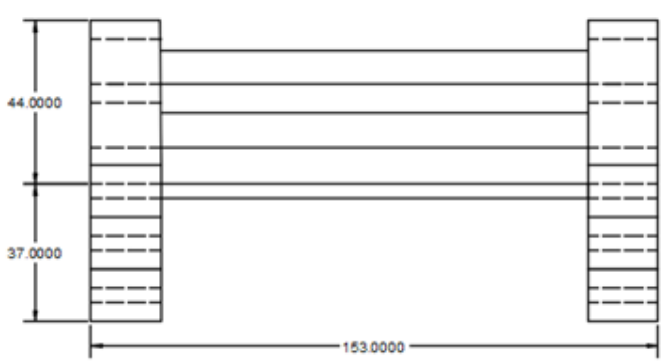

b) vista frontal 


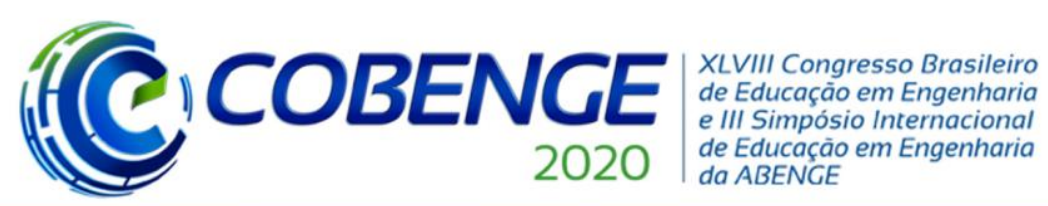

"Os desafios para formar hoje o engenheiro do amanhã"

O resultado final da oficina e dos banco podem ser visto na Figura 5.

Fonte: Autores (2019)

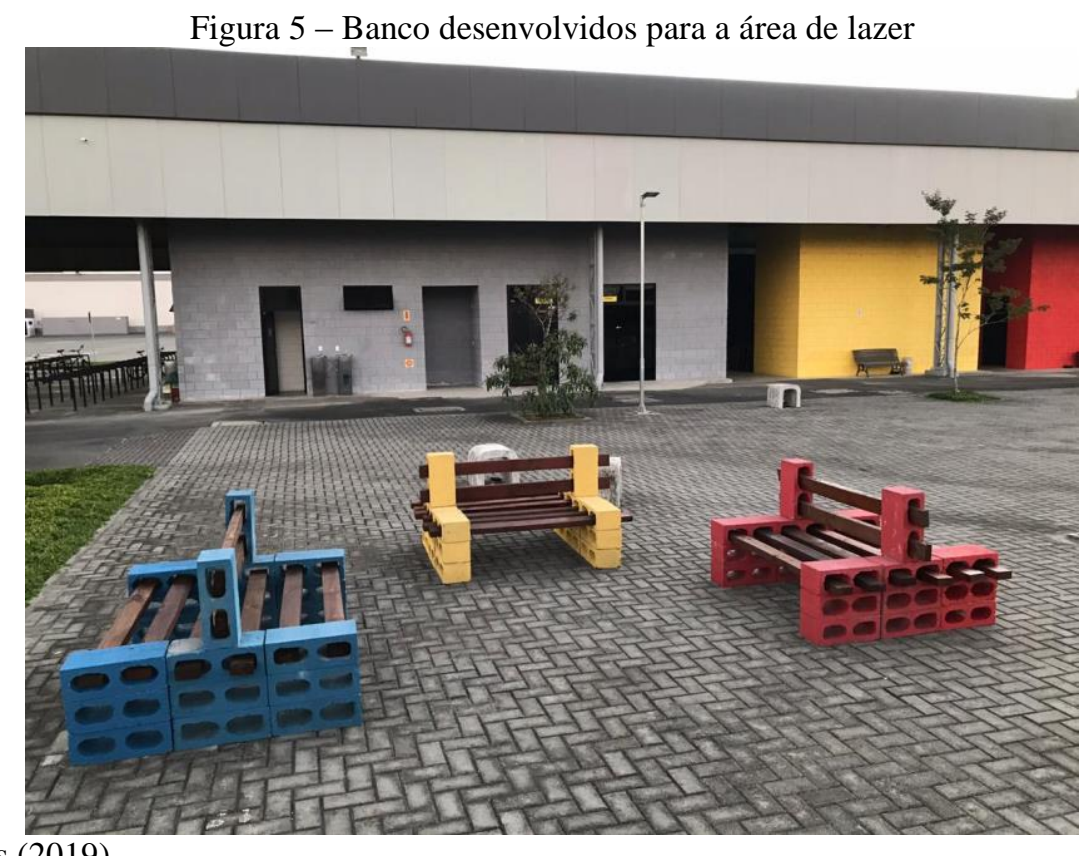

A interação entre comunidade acadêmica e alunos de escolas públicas foi um grande sucesso. Houve uma troca de experiências proveitosa dos dois lados.

Ao mesmo tempo em que os alunos das escolas puderam sentir um pouco do que é feito nas universidades, aprender um pouco mais sobre sustentabilidade e aproveitamento de materiais, os participantes do PET EMB tiveram a oportunidade de colocar alguns conhecimentos adquiridos nos seus respectivos cursos em prática.

A comunidade acadêmica do campus de Joinville também teve proveito já que a área de lazer ajuda a suprir a falta espaços para convivência.

\section{CONSIDERAÇÕES FINAIS}

O desenvolvimento econômico e de tecnologias está diretamente ligado a questões de sustentabilidade nas mais diversas áreas. Pensamentos críticos acerca da utilização da forma correta e eficiente dos recursos naturais são fundamentais para um futuro próspero.

Projetos de extensão são a ponte entre a universidade e a comunidade no geral, portanto, fomentar projetos como esse são fundamentais para o sucesso dessa relação.

Juntar tais projetos com problemas do cotidiano, como questões de sustentabilidade e falta de espaços físicos, por exemplo, é melhor forma de otimizar tempo e recursos. Além de servirem para ampliar conhecimentos, experiências e percepções.

Para projetos futuros é possível pensar em formar de ampliar tais áreas de lazer, como deixa-las mais aconchegantes e seguras para diferentes tipos de climas. 


\section{Agradecimentos}

Os autores agradecem o Ministério da Educação pela oportunidade de bolsa dentro do Programa de Educação Tutorial das Engenharias da Mobilidade (PET EMB). À universidade pelo apoio ao programa e apoio ao nosso projeto. Ao nosso tutor pelo suporte em todo projeto, e o suporte e trabalho conjunto dos colegas de equipe.

\section{REFERÊNCIAS}

AZEVEDO, M.; SILVA, C.R. A importância de inserir a temática sustentabilidade durante a graduação de engenharia para a formação de profissionais com visão crítica. XLVIII Congresso Brasileiro de Educação em Engenharia, 2019, Fortaleza.

BRASILEIRO, L. L.; MATOS, J. M. E. Revisão bibliográfica: reutilização de resíduos da construção e demolição na indústria da construção civil. Revista Cerâmica, São Paulo, v. 61, n. 358, p. 178-189, 2015.

CARVAlHO,R. et al. O Programa de Educação Tutorial (PET) no contexto da crise econômica brasileira. Extensão em Foco, [s.1.], v. 1, n. 15, p.28-45, 6 fev. 2018. Universidade Federal do Paraná.

FIALHO, P. et al. Contribuições do II fórum de pesquisa e extensão - construção de cidades sustentáveis. In: XLVI Congresso Brasileiro de Educação em Engenharia, 2018, Salvador.

Fundo Nacional de Desenvolvimento da Educação. Educação Tutorial. Disponível em: $<$ https://www.fnde.gov.br/index.php/programas/bolsas-e-auxilios/eixos-de-atuacao/educacaotutorial>. Acesso em: 01 fev. 2020.

JOHN, V. M. \& AGOPYAN, V. Reciclagem de resíduos da construção. São Paulo: Secretaria de Estado do Meio Ambiente / Cetesb, 2000.

JUSTINO, P. et al. Desenvolvimento de uma carenagem para veículo off-road por meio de materiais recicláveis. In: XLVI Congresso Brasileiro de Educação em Engenharia, 2018, Salvador.

Ministério da Educação. Apresentação - PET. Disponível em: <http://portal.mec.gov.br/pet>. Acesso em: 01 fev. 2020.

PEREIRA, P.Construção Sustentável: o desafio. 106 f.Monografia (Graduação) Universidade Fernando Pessoa, Porto, 2009.

TESSARO, A. B.; SÁ, J. S.; SCREMIN, L. B. Quantificação e classificação dos resíduos procedentes da construção civil e demolição no município de Pelotas, RS. Revista Ambiente Construído, Porto Alegre, v. 12, n. 2, p. 121-130,2012. 


\title{
EXTENSION PROJECT FOR THE CONTRUSION OF A LEISURE AREA AT THE FEDERAL UNIVERSITY OF SANTA CATARINA IN THE JOINBILLE CAMPUS
}

\begin{abstract}
Currently, sustainability is being a constant theme in several areas, using the theme coupled with the demand for common areas at the university or the Tutorial Education Program for Mobility Engineering (PET EMB) developed or the Leisure Area project in order to carry out this task. column. The project took place through a partnership with the community at the National Week of Science and Technology (SNCT) of 2019 in a workshop given by public agencies in the city of Joinville, Santa Catarina, in which banks were made with materials of easy access and low cost. The initiative was a success, featuring an academic community from the Federal University of Santa Catarina, on the Joinville campus, with a new leisure area for students, teachers and public servants.
\end{abstract}

Key-words: Recreation. Sustainability.Extension. 